\title{
Removal of Chloride in the Kraft Chemical Recovery Cycle of Pulp Mills Using the Ion-Exchange Process
}

\author{
Licínio Manuel G. A. Ferreira* \\ Department of Chemical Engineering, University of Coimbra, Pólo II ,
} Pinhal de Marrocos, 3030-290 Coimbra, Portugal

\section{Luís Amaral and Luís Machado}

RAIZ, Research Institute on Forestry and Paper, Quinta de S. Francisco, 3801-501 Eixo-Aveiro, Portugal

\begin{abstract}
High levels of chloride in the kraft recovery cycle of pulp mills can cause serious problems, particularly in recovery boiler operation. The treatment of ash collected from the electrostatic precipitator (ESP) for chloride removal was investigated experimentally using the ion-exchange process based on an amphoteric resin (BIORAD AG 11 A8). Saturation and regeneration experiments in a fixed bed were carried out for different flow rates. Experimental adsorption results obtained in the saturation step were well predicted with a mathematical model that takes into account dispersed plug flow for the bulk liquid, external mass-transfer resistance, intraparticle mass transfer by pore diffusion, and instantaneous equilibrium of adsorption at the pore/wall interface. The equilibrium was modeled using an extended Langmuir $-F$ reundlich isotherm for three components $\left(\mathrm{Cl}^{-}, \mathrm{SO}_{4}{ }^{2-}\right.$, and $\left.\mathrm{CO}_{3}{ }^{2-}\right)$ based on single-component equilibrium data. The resin performance was tested during cyclic operation, in which a chloride removal efficiency of higher than $89 \%$ was achieved, along with a sulfate recovery of $67-74 \%$.
\end{abstract}

\section{Introduction}

A high concentration level of chloride in the recovery cycle of kraft pulp mills is known to cause serious problems in recovery boiler operation. The boiler burns black liquor, which is a heterogeneous aqueous sol ution of various organic and inorganic substances. ${ }^{1}$ The inorganic material consists mainly of residual effective alkalis, sulfide, sulfate, carbonate, chloride, thiosulfate, and oxalate. ${ }^{2}$ The exact composition of the black liquor depends on the wood species, the pulp yield, and the alkali charge used. The sources and amounts of $\mathrm{Cl}$ entering a mill vary from one mill to another depending on the type of wood, the degree of closure, and the location of the mill (inland or coastal). For inland mills, the wood is the main source of input for $\mathrm{Cl}$, and its concentration in strong black liquor (BLS) is typically $0.1-0.8 \%$ of the liquor dry solid. However, for coastal mills transporting their logs on seawater, the $\mathrm{Cl}$ content can be as high as 3-5\%, and in closed processes, it can rise even higher. ${ }^{2,3}$ Studies have shown that the chloride concentration is one of the most significant factors affecting the melting properties of the ash in the boiler ${ }^{3,4}$ Some of these ash particles are dragged with the gas stream and form deposits on tube surfaces in the upper furnace of the recovery boiler, and if such deposits are not periodically removed, they can plug the flue gas passages. Thus, excessive deposit accumulation decreases the boiler capacity and causes severe losses of production. Also, the risk of occurrence of a corrosive environment that can damage tubes increases drastically. The current level of chloride in the recovery cycle of some mills requires that boilers be shut down for water washing as frequently as every 3 months. If this

* To whom correspondence should be addressed. E-mail: Iferreira@eq.uc.pt. level is maintained at a minimal value in the BLS, the operating availability of the recovery boiler can be extended beyond 6 months without cleaning and without noticeable signs of fouling or plugging.

A few processes such as leaching, ${ }^{5}$ evaporation/ crystallization, ${ }^{6}$ electrodialysis, ${ }^{7}$ and ion exchange ${ }^{8,9}$ have been applied to reduce the chloride level in ash captured in the electrostatic precipitator (ESP) before it is recycled to the liquor cycle. This stream is rather enriched in chloride and is easier to handle than other alternatives, such as the green and white liquor, which are particularly corrosive at the air/liquor interface where the leakage of air causes an increase in the concentration of thiosulfates. ${ }^{10}$ However, it is possible to remove chloride by evaporating the white liquor ${ }^{11}$ or by cooling the green liquor to temperatures below 20 ${ }^{\circ} \mathrm{C}$ followed by evaporation and subsequent precipitation of $\mathrm{NaCl} .^{12}$ The first process was devel oped by Ahlstrom but has not used, whereas the second was practiced in the closed cycle mill at Great Lakes Forest Products Limited, resulting in several operational problems, such as corrosion problems in the evaporators. ${ }^{13}$

In some kraft mills, it is common practice to simply purge part of the total ash collected in the preci pitator, but this causes a significant loss of sodium sulfate and sodium carbonate. This sodium must be replaced, so there is an additional cost for makeup chemicals. A preliminary economic analysis reported by Ferreira et al. ${ }^{14}$ for different ash treatment alternatives (purging, leaching, evaporation/crystallization, and ion exchange), indicated that, in terms of maintenance costs, purging is indeed the most expensive alternative, mainly be cause of the sulfate makeup. I on exchange was found to be an attractive process for efficient chloride removal as it is one of the less expensive altenatives.

The selective removal of chloride from ESP using the Recoflo ion-exchange technology employs fine particles, 
Table 1. Physical Properties of the AG 11 A8 Resin

\begin{tabular}{ll}
\hline \multicolumn{1}{c}{ property } & value \\
\hline wet density, $\rho \mathrm{h}$ ( $\mathrm{g}$ of wet resin/L of resin) & 1027 \\
apparent density, $\rho_{\mathrm{a}}$ (g of dry resin/L of resin) & 681 \\
particle porosity, $\epsilon_{\mathrm{p}}$ & 0.46 \\
moisture content $(\%)$ & 33 \\
average particle size $(\mathrm{mm})$ & 0.23
\end{tabular}

short column heights, and high flow rates. In the work reported by J emaa et al., ${ }^{9}$ the ashes are dissolved in warm water $\left(40-50^{\circ} \mathrm{C}\right)$, and then the previously filtered solution is percolated through a fixed bed packed with a amphoteric resin that exhibits greater affinity for sodium chloride than for other compounds such as sodium sulfate. Thus, during this operation (upstroke step), the $\mathrm{NaCl}$ is adsorbed by the resin, and the purified solution $\left(\mathrm{Na}_{2} \mathrm{SO}_{4} / \mathrm{Na}_{2} \mathrm{CO}_{3}\right)$ is collected and recycled to the kraft recovery cycle. Sodium chloride is released by the resin during the downstroke step, in which water is passed through the bed. The system alternates automatically between the upstroke and downstroke every 2 min. The work presented here deals with a similar ion-exchange system in which the operation steps are carried out with longer cycle times, approximately $12 \mathrm{~min}$, and the size of the resin (ion retardation resin $A G 11 \mathrm{~A} 8$ ) particles used is higher than the standard fine mesh size utilized in the Recoflo systems. In this study, the attention is focused on the dynamics of the process based on saturation and regeneration fixed-bed experiments. Saturation was modeled using an extended Langmuir-F reundlich isotherm for three components based on single-component equilibrium data. Several cyclic experiments were also carried out, to evaluate the resin performance.

\section{Material and Methods}

Equilibrium isotherms were determined by batch experiments at a temperature of $45^{\circ} \mathrm{C}$ using a Unitronic (Selecta) shaker and a thermostatic bath. In these experiments, a known mass $(2 \mathrm{~g})$ of resin Bio-Rad AG 11 A8 was poured into volumetric flasks with $20 \mathrm{~mL}$ of initial solution with concentrations of $\mathrm{NaCl}, \mathrm{Na}_{2} \mathrm{SO}_{4}$, and $\mathrm{Na}_{2} \mathrm{CO}_{3}$ ranging from 32 to $1300 \mathrm{mmol} / \mathrm{L}$, from 20 to $1500 \mathrm{mmol} / \mathrm{L}$, and from 60 to $140 \mathrm{mmol} / \mathrm{L}$, respectively. The flasks were then placed in the shaker for 48 h (time required to reach equilibrium). After equilibrium was reached, the solution was separated from the resin and the concentrations of $\mathrm{Cl}^{-}, \mathrm{SO}_{4}{ }^{2-}$, and $\mathrm{CO}_{3}{ }^{2-}$ were determined by titration and ion chromatography techniques. The physical properties of the resin used are listed in Table 1.

Fixed-bed experiments (saturation and regeneration) were carried out in a jacketed column $(26 \times 500 \mathrm{~mm}$, Pharmacy), with the flow controlled by a peristaltic pump (I smatec-BVP). The experimental conditions for these runs are summarized in Table 2. During the saturation step, an aqueous solution prepared from industrial ESP ash was passed through the column, and fractions of the treated feed, at the col umn outl et, were collected at regular intervals of time for analysis. In the regeneration step, distilled water was percolated through the column, and fractions of the eluted solution were also collected. The ESP ash was obtained from a Portuguese pulp mills using Eucal yptus gl obulus (hardwood) with larger chloride concentration levels in the recovery cycle. To prepare the feed solution, the ashes were dissolved in water to yield a concentration of about
Table 2. Experimental Conditions for Fixed-Bed Experiments $^{\mathrm{a}}$

\begin{tabular}{ccccc}
\hline run & $\begin{array}{c}\mathrm{C}_{\text {chloride, }}(\mathrm{g} / \mathrm{L}) \\
1 \mathrm{a}\end{array}$ & $\begin{array}{c}\mathrm{C}_{\text {sulfate,f }}(\mathrm{g} / \mathrm{L}) \\
24.00\end{array}$ & $\begin{array}{c}\mathrm{C}_{\text {carbonate,f }} \\
(\mathrm{g} / \mathrm{L})\end{array}$ & feed $\mathrm{pH}$ \\
\hline $\mathrm{2a}$ & 25.50 & 146.10 & 2.40 & 8.1 \\
& & 73.0 & -
\end{tabular}

a Bed properties: $\epsilon=0.45, \mathrm{~L}(\mathrm{~cm})=22$ (runs $1 \mathrm{a} / \mathrm{b}$ ) and 26 (runs $2 \mathrm{a} / \mathrm{b})$. Flow conditions: $U\left(\mathrm{~cm}^{3} / \mathrm{min}\right)=15.3, \mathrm{u}(\mathrm{cm} / \mathrm{min})=3.06$ and $\tau(\min )=3.24$ for runs $1 \mathrm{a} / \mathrm{b} ; \mathrm{U}\left(\mathrm{cm}^{3} / \mathrm{min}\right)=40.0, \mathrm{u}(\mathrm{cm} / \mathrm{min})$ $=7.77$, and $\tau(\min )=1.51$ for runs $2 \mathrm{a} / \mathrm{b}$.

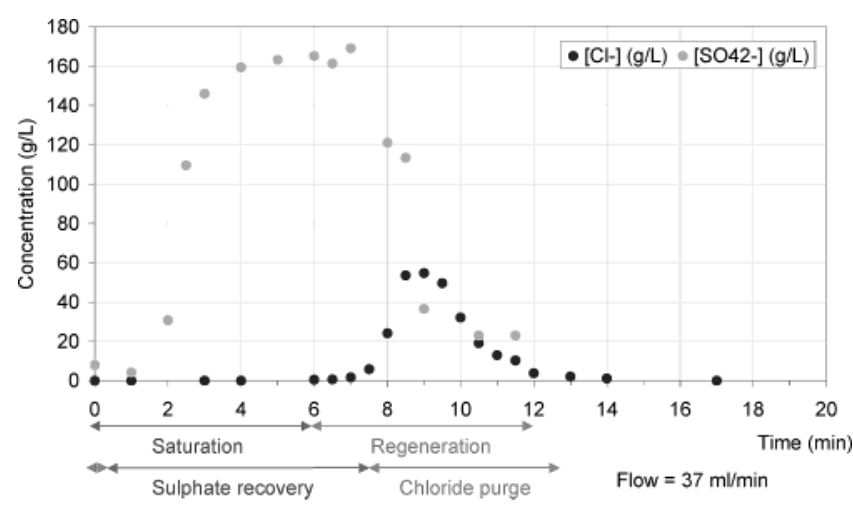

Figure 1. Saturation/regeneration cycle and sulfate recovery/ chloride purge times.

Table 3. Composition of ESP Ashes

\begin{tabular}{cc}
\hline chemical species & weight \% in ESP ash \\
\hline sulfate & $32-37$ \\
sodium & $30-40$ \\
carbonate & $16-18$ \\
chloride & $5-7$ \\
potassium & 4
\end{tabular}

$30-40 \%$ of dissolved solids and then filtered under vacuum using a Buchner funnel to remove the suspended solids. The concentration ranges of the principal species present in the samples of ESP ash and measured using analytical techniques as described above are reported in Table 3 . The temperature of $45^{\circ} \mathrm{C}$ for the experiments was chosen on the basis of the thermal balance after the necessary dilution of the hot ash stream collected from the el ectrostatic preci pitator with industrial water.

Cyclic operation experiments were performed under conditions identical to those used for the fixed-bed experiments with the exception of some operating conditions, as described below, which were changed to approach the industrial-scale conditions. Thus, the saturation and regeneration steps were carried out at a flow rate of $37 \mathrm{~mL} / \mathrm{min}$, at 45 and $20^{\circ} \mathrm{C}$, respectively. Fresh water collected from the mill was used for the preparation of the ash solution ( $\pm 3 \%$ dissolved solids) and for the regeneration of the bed. The cycle times were defined on the basis of a previous experiment run under the same conditions. The results of this last experiment were also used to define the collecting time intervals of sulfate-rich solution and of chloride purge, aiming at minimizing sulfate and sodium losses without compromising the chl oride removal efficiency. The saturation/ regeneration cycles and sulfate recovery/chloride purge were shifted automatically using a timer and el ectrical valves in a specially designed laboratory apparatus (see Figure 2), according to the times depicted in Figure 1.

The chloride and sulfate concentrations were periodically determined by titration techniques in the sulfate recovery and chloride purge solutions, at the end of a 


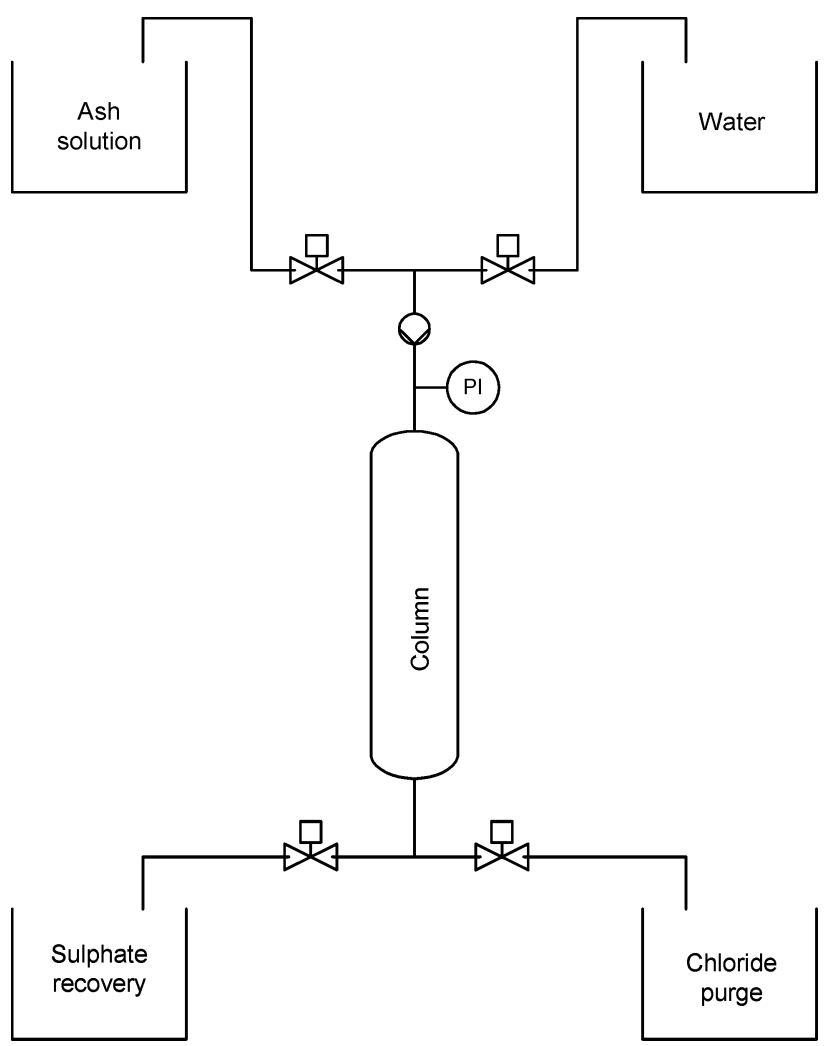

Figure 2. Laboratory apparatus used in the cyclic operation experiments.

period with a certain number of cycles. The chloride removal efficiency and sulfate loss were calculated for each period using the measured concentrations and the collected volume of each fraction.

\section{Modeling}

3.1. Adsorption Equilibrium Model. To describe quantitatively the adsorption experimental data obtained by the technique batch, we used the LangmuirFreundlich equation

$$
q_{i}=\frac{a_{i} C_{i}^{n_{i}}}{1+a_{i} C^{n_{i}}}
$$

where $\mathrm{q}_{\mathrm{i}}$ (mmol of component $\mathrm{i}$ adsorbed/g of wet resin) and $\mathrm{C}_{i}$ ( $\mathrm{mmol} / \mathrm{L}$ of solution) are the concentrations in equilibrium of component i $\left(\mathrm{Cl}^{-}, \mathrm{SO}_{4}{ }^{2-}\right.$, and $\left.\mathrm{CO}_{3}{ }^{2-}\right)$ in the adsorbed and liquid phases, respectively.

3.2. Dynamic Model for Fixed-Bed Adsorption and Parameter Estimation. A model was developed to describe the dynamic behavior of the system during the saturation step, namely, the species concentrations in the solution at the outlet of the column as a function of time (breakthrough curve). The model includes pore diffusion, film mass-transfer resistance, and axial dispersion. Dimensionless model equations are as follows:

Mass balance for the fluid phase

$$
\begin{aligned}
& \frac{\partial X_{i}\left(z^{*}, \theta\right)}{\partial \theta}=\frac{1}{\operatorname{Pe}} \frac{\partial^{2} X_{i}\left(z^{*}, \theta\right)}{\partial z^{*}}-\frac{\partial X_{i}\left(z^{*}, \theta\right)}{\partial Z^{*}}- N_{f}\left[X_{i}\left(z^{*}, \theta\right)-\right. \\
&\left.X_{p i}\left(1, z^{*}, \theta\right)\right]
\end{aligned}
$$

where $\mathrm{i}=1\left(\mathrm{Cl}^{-}\right), 2\left(\mathrm{SO}_{4}{ }^{2-}\right)$, and $3\left(\mathrm{CO}_{3}{ }^{2-}\right)$
Mass balance inside particles

$$
\begin{aligned}
\frac{\rho_{\mathrm{h}}}{\mathrm{C}_{\mathrm{Ei}}} \frac{\partial \mathrm{q}_{\mathrm{i}}\left(\mathrm{u}^{*}, \mathrm{z}^{*}, \theta\right)}{\partial \theta}+\epsilon_{\mathrm{p}} \frac{\partial \mathrm{X}_{\mathrm{pi}}\left(\mathrm{u}^{*}, \mathrm{z}^{*}, \theta\right)}{\partial \theta}= \\
\mathrm{N}_{\mathrm{Di}}\left[\frac{\partial^{2} \mathrm{X}_{\mathrm{pi}}\left(\mathrm{u}^{*}, \mathrm{z}^{*}, \theta\right)}{\partial \mathrm{u}^{*}}+\frac{2}{\mathrm{u}^{*}} \frac{\partial \mathrm{X}_{\mathrm{pi}}\left(\mathrm{u}^{*}, \mathrm{z}^{*}, \theta\right)}{\partial \mathrm{u}^{*}}\right]
\end{aligned}
$$

Multicomponent equilibrium adsorption at the pore/wall interface described by the extended Langmuir-Freundlich model

$$
\mathrm{q}_{\mathrm{i}}=\frac{\mathrm{a}_{\mathrm{i}}\left(\mathrm{C}_{\mathrm{Ei}} \mathrm{X}_{\mathrm{pi}} / \eta_{\mathrm{i}}\right)^{\mathrm{n}_{\mathrm{i}}}}{1+\sum_{\mathrm{j}=1}^{3} \mathrm{~b}_{\mathrm{j}}\left(\mathrm{C}_{\mathrm{Ej}} \mathrm{X}_{\mathrm{pj}} / \eta_{\mathrm{j}}\right)^{\mathrm{n}_{\mathrm{j}}}}
$$

where $a_{i}, b_{i}$, and $n_{i}$ are given by the individual Langmuir-F reundlich isotherm (eq 1 ) and $\eta_{\text {i }}$ represents the interaction terms to quantify the competitive adsorption in multicomponent systems. ${ }^{15}$

This system of equations is subject to the following initial and boundary conditions:

Initial conditions

$$
\theta=0 \quad \mathrm{X}_{\mathrm{i}}\left(\mathrm{z}^{*}, 0\right)=\mathrm{X}_{\mathrm{oi}} \text { and } \mathrm{X}_{\mathrm{pi}}\left(\mathrm{u}^{*}, \mathrm{z}^{*}, 0\right)=\mathrm{X}_{\mathrm{oi}}
$$

Boundary conditions

$$
u^{*}=\left.0 \quad \frac{\partial \mathrm{X}_{\mathrm{pi}}\left(\mathrm{u}^{*}, \mathrm{z}^{*}, \theta\right)}{\partial \mathrm{u}^{*}}\right|_{\mathrm{u}^{*}=0}=0
$$

$\mathrm{u}^{*}=1$

$$
\begin{aligned}
& \mathrm{N}_{\mathrm{fi}}\left[\mathrm{X}_{\mathrm{i}}\left(\mathrm{Z}^{*}, \theta\right)-\mathrm{X}_{\mathrm{pi}}\left(1, \mathrm{z}^{*}, \theta\right)\right]= \\
& \left.3 \frac{1-\epsilon}{\epsilon} \mathrm{N}_{\mathrm{Di}} \frac{\partial \mathrm{X}_{\mathrm{pi}}\left(\mathrm{u}^{*}, \mathrm{z}^{*}, \theta\right)}{\partial \mathrm{u}^{*}}\right|_{\mathrm{u}^{*}=1}
\end{aligned}
$$

The above equations are written in terms of dimensionless variables: $X_{i}=C_{i} / C_{E i}, X_{p i}=C_{p i} / C_{E i}$ are the dimensionless concentrations of species $i$ in the bulk liquid phase and in the liquid inside particle pores, respectively; $\theta=\mathrm{t} / \tau$ is a reduced time, where $\tau$ is the bed space time; $z^{*}=z / L$ is the reduced axial coordinate, where $L$ is the fixed-bed length; and $u^{*}=r / R$ is the reduced particle radial coordinate, where $R$ is the adsorbent particle radius. The dimensionless groups are the Peclet number

$$
\mathrm{Pe}=\frac{\mathrm{uL}}{\epsilon \mathrm{D}_{\mathrm{ax}}}
$$

where $D_{a x}$ is the axial dispersion coefficient; the number of mass-transfer units transported by pore diffusion for species $\mathrm{i}$

$$
\mathrm{N}_{\mathrm{Di}}=\frac{\tau \epsilon_{\mathrm{p}} \mathrm{D}_{\mathrm{pi}}}{\mathrm{R}^{2}}
$$

where $D_{p i}=D_{\text {mi }} / \tau_{p}$ is the species i effective diffusivity and $\tau_{\mathrm{p}}$ is the tortuosity factor; and the number of film mass-transfer units for species i

$$
\mathrm{N}_{\mathrm{fi}}=\frac{3(1-\epsilon) \mathrm{k}_{\mathrm{fi}} \tau}{\epsilon \mathrm{R}}
$$

where $k_{f i}$ is the film mass-transfer coefficient for species i. 
7124 Ind. Eng. Chem. Res., Vol. 43, No. 22, 2004

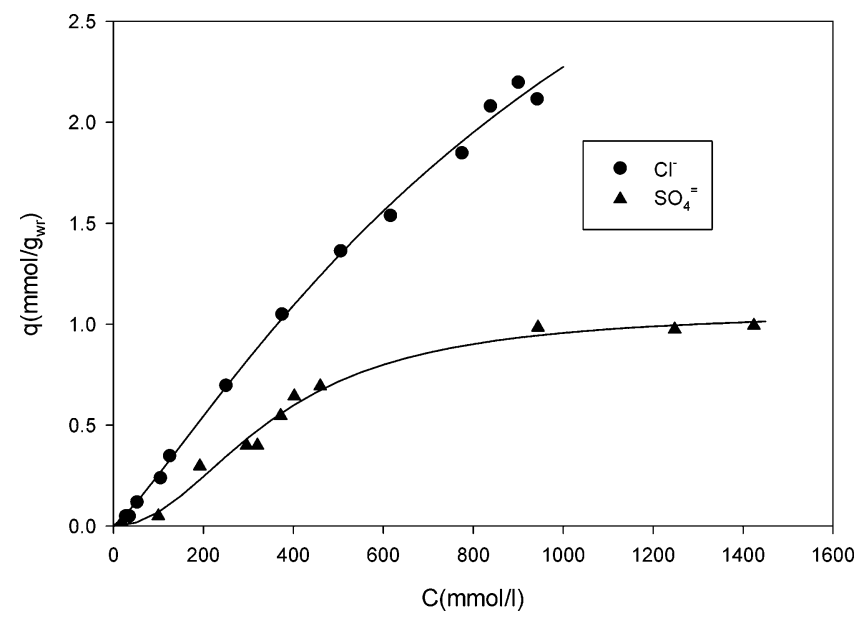

Figure 3. Equilibrium isotherms at $45^{\circ} \mathrm{C}$ for Bio-Rad resin in $\mathrm{NaCl}$ and $\mathrm{Na}_{2} \mathrm{SO}_{4}$ solutions.

Numerical solution of egs 2-7 was performed by discretizing eq 3 in the radial direction using orthogonal collocation in $\mathrm{N}_{\mathrm{E}}$ finite elements with cubic Hermite polynomials as basis functions. This led to a new boundary value problem of $\mathrm{N}_{\text {comp }}\left(2 \mathrm{~N}_{\mathrm{E}}+1\right)$ (where $\mathrm{N}_{\text {comp }}$ is the number of components) parabolic PDEs in the independent variables $z^{*}$ and $\theta$ that were numerically integrated with the PDECOL package. ${ }^{16}$

To evaluate $\mathrm{N}_{\mathrm{fi}}$, the bed porosity $\epsilon$ was experimentally determined, and the film mass-transfer coefficient, $\mathrm{k}_{\mathrm{f}}$ was estimated using the empirical correlation, valid for low Reynolds numbers $(\operatorname{Re}<50)$

$$
\frac{\mathrm{Sh}}{\mathrm{Sc}^{1 / 3} \mathrm{Re}}=0.91 \operatorname{Re}^{-0.51} \psi
$$

with

$$
\begin{gathered}
S h=\frac{k_{f} d_{p}}{D_{m}} \\
\operatorname{Re}=\frac{u d_{p} \rho}{[\mu \sigma(1-\epsilon) \psi]}
\end{gathered}
$$

and

$$
\mathrm{Sc}=\frac{\mu}{\rho \mathrm{D}_{\mathrm{m}}}
$$

The molecular diffusivities of $\mathrm{Cl}^{-}, \mathrm{SO}_{4}{ }^{2-}$, and $\mathrm{CO}_{3}{ }^{2-}$ were estimated by the Nernst equation ${ }^{17}$

$$
\mathrm{D}_{\mathrm{mi}}=2.661 \times 10^{-7} \lambda_{\mathrm{i}} /\left|\mathrm{z}_{\mathrm{i}}\right|
$$

where $\lambda_{i}$ and $z_{i}$ are the equival ent ionic conductivity and the charge for species $i$, respectively. The values of $D_{\text {mi }}$ obtained were also used to cal culate the parameter $\mathrm{N}_{\mathrm{Di}}$, in which, for the evaluation of the effective diffusivity $D_{\mathrm{pi}}\left(=\mathrm{D}_{\mathrm{mi}} / \tau_{\mathrm{p}}\right)$, the tortuosity factor was predicted as being 2.17, according to the random-pore model of Wakao and Smith, ${ }^{18} \tau_{\mathrm{p}}=1 / \epsilon_{\mathrm{p}}$.

\section{Results and Discussion}

4.1. Analysis of Isotherm Data. Results of singlesolute adsorption equilibrium data for aqueous $\mathrm{NaCl}$, $\mathrm{Na}_{2} \mathrm{SO}_{4}$, and $\mathrm{Na}_{2} \mathrm{CO}_{3}$ solutions being adsorbed onto resin are shown in Figures 3 and 4. According to the

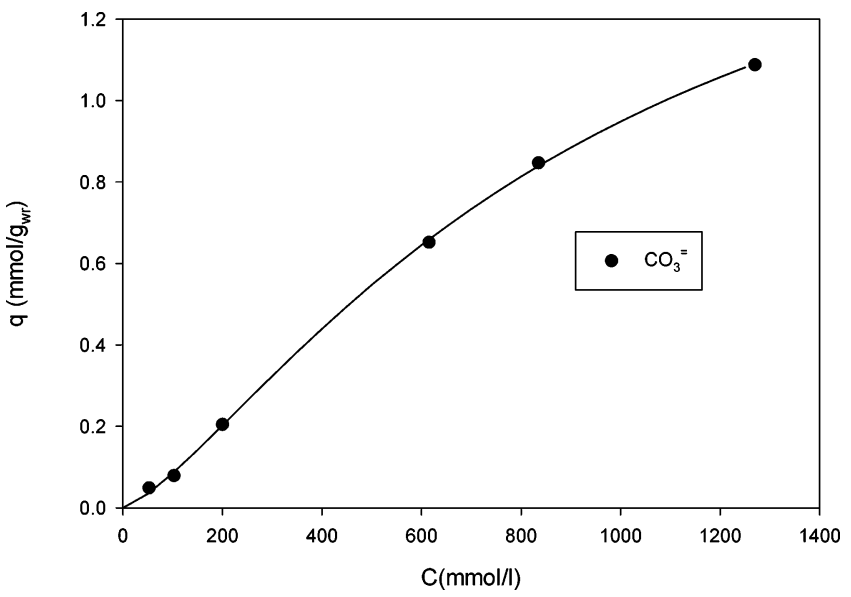

Figure 4. Equilibrium isotherm at $45{ }^{\circ} \mathrm{C}$ for Bio-Rad resin in $\mathrm{Na}_{2} \mathrm{CO}_{3}$ solution.

manufacturer, the resin is a styrene divinylbenzene cross-linked rigid polymer lattice with attached quaternary ammonium groups (strong basic anion-exchange groups) and also having a linear, relatively flexible acrylic acid polymer based on carboxylic groups (weak acidic cation-exchange groups). Thus, the resin is of amphoteric type (containing both cation-exchange and anion-exchange groups), i.e., when brought into contact with aqueous salt solutions, the ions are adsorbed without exchange. ${ }^{19} \mathrm{In}$ fact, the small $\mathrm{pH}$ change observed in the samples collected from the batch experiments, when compared with the initial and final (equilibrium) conditions, is not caused by any ion-exchange reaction. Hence, an approach based on models used to describe adsorption processes should be suitable for predicting the equilibrium distribution of solutes be tween the solid and liquid phases. Thus, the experimental points $\left(q_{i}, C_{i}\right)$ of the adsorption equilibrium data for each studied component were fitted by the Langmuir-Freundlich equation. The values found for the parameters are as follows: $a_{1}=1.10 \times 10^{-3}, b_{1}=2.20$ $\times 10^{-4}$, and $n_{1}=1.20$ for chloride; $a_{1}=4.67 \times 10^{-6}, b_{1}$ $=4.38 \times 10^{-6}$, and $n_{1}=2.10$ for sulfate; and $a_{1}=1.76$ $\times 10^{-4}, b_{1}=9.77 \times 10^{-5}$, and $n_{1}=1.35$ for carbonate.

The single-component equilibrium data illustrated in Figures 3 and 4 show that the adsorptive capacity of the resin depends on the species, the chloride ion being the most adsorbed, as expected.

4.2. Analysis of Saturation and Regeneration Curves. Adsorption and desorption breakthrough curves corresponding to the saturation and regeneration steps, respectively, in the fixed bed are shown in Figures 5 and 6. It should be noted that the industrial ash streams treated in the two experiments were collected in different periods of the mill operation. The ash sample used in run 2 is quite similar to that used in run 1 in terms of chloride and sulfate concentrations, but it contains a higher amount of carbonate. Table 4 shows also the values used for the model parameters in the simulation of the saturation experiments. A reasonable agreement is observed between experimental and calculated concentration curves for species i (see Figure $5 a, b$ ), with the adjustable parameters being the Peclet number, $\mathrm{Pe}$, and the interaction factors, $\eta_{\mathrm{i}}$. The values found for $\eta_{\mathrm{i}}$ are $\eta_{\mathrm{Cl}}=0.3, \eta_{\mathrm{SO}_{4}}=4$, and $\eta_{\mathrm{CO}_{3}}=4$.

Figure $5 a, b$ illustrates the effect of the flow rate on the adsorption (saturation) breakthrough curves. As expected, at low flow rates, a longer contact between the phases is promoted, and this leads to larger break- 
Ind. Eng. Chem. Res., Vol. 43, No. 22, 20047125
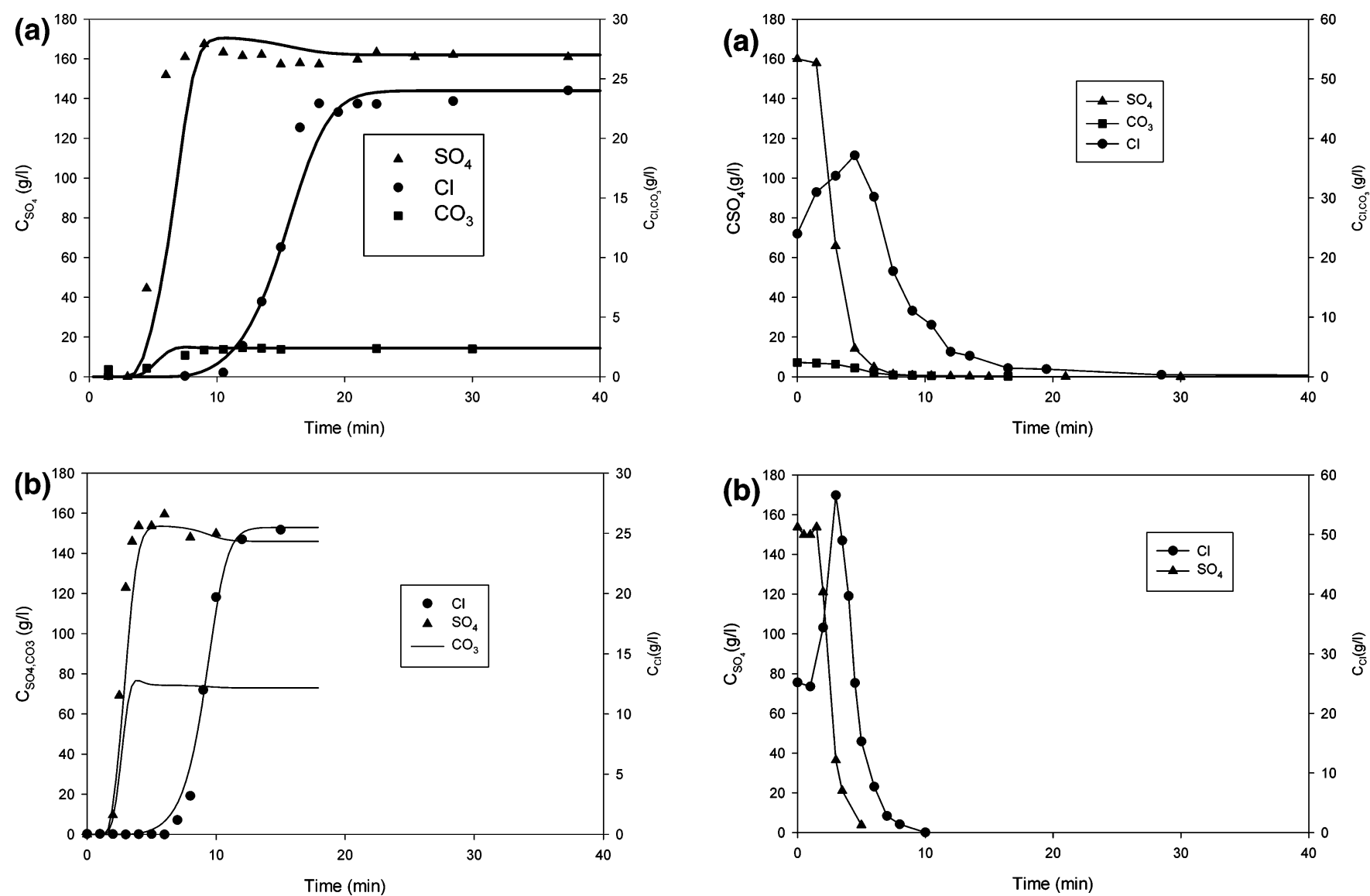

Figure 5. (a) Adsorption breakthrough curves (saturation) for mixtures of $\mathrm{Cl}^{-}, \mathrm{SO}_{4}{ }^{2-}$, and $\mathrm{CO}_{3}{ }^{2-}$ in ash: (a) run 1 , (b) run 2. The simulated data are presented as solid lines, whereas the experimental data are presented as symbols.

Table 4. Parameter Values Used in the Simulations of the Saturation Step

\begin{tabular}{cll}
\hline parameter & run 1 & run 2 \\
\hline $\mathrm{Pe}$ & 120 & 120 \\
$\mathrm{~N}_{\mathrm{D} 1}$ & 6.63 & 3.08 \\
$\mathrm{~N}_{\mathrm{D} 2}$ & 3.47 & 1.61 \\
$\mathrm{~N}_{\mathrm{D} 3}$ & 3.00 & 1.39 \\
$\mathrm{~N}_{\mathrm{f}}$ & 79.32 & 58.24 \\
$\mathrm{~N}_{\mathrm{f} 2}$ & 51.48 & 37.80 \\
$\mathrm{~N}_{\mathrm{f} 3}$ & 46.78 & 34.34
\end{tabular}

through times. This effect can also be seen in Figure $6 a, b$. Decreasing the flow rate results in a longer time needed to regenerate the bed. Moreover, a longer time is needed to remove the chloride from the fixed bed than the other species; this is because chloride has a higher affinity for the adsorbent. At high flow rates, the regeneration of the bed is faster, and the chloride concentration exhibits a higher maximum peak. The behavior of the regeneration curves can be better explained by the influence of the regenerant on the adsorption equilibrium of the species on the adsorbent. However, for the resin studied, it is still unclear how this equilibrium is affected when the bed is regenerated with water. One might expect that the rapid displacement of the chloride ion from the bed by fresh water should be accompanied by the breakage of bonds or by significant structural changes of the resin sites as reported by Rice and $\mathrm{Foo}^{20}$

4.3. Saturation Simulation. Effect of Axial Dispersion. The effects of axial dispersion on the saturation curves are illustrated in Figure 7. The axial dipersion measured by the Peclet number, $\mathrm{Pe}$, is a

Figure 6. (a) Desorption breakthrough curves (regeneration with water) for species (a) $\mathrm{Cl}^{-}, \mathrm{SO}_{4}{ }^{2-}$, and $\mathrm{CO}_{3}{ }^{2-}$ at flow rate $\mathrm{U}=15$ $\mathrm{mL} / \mathrm{min}$, and (b) $\mathrm{Cl}^{-}$and $\mathrm{SO}_{4}{ }^{2-}$ at flow rate $\mathrm{U}=40 \mathrm{ml} / \mathrm{min}$.

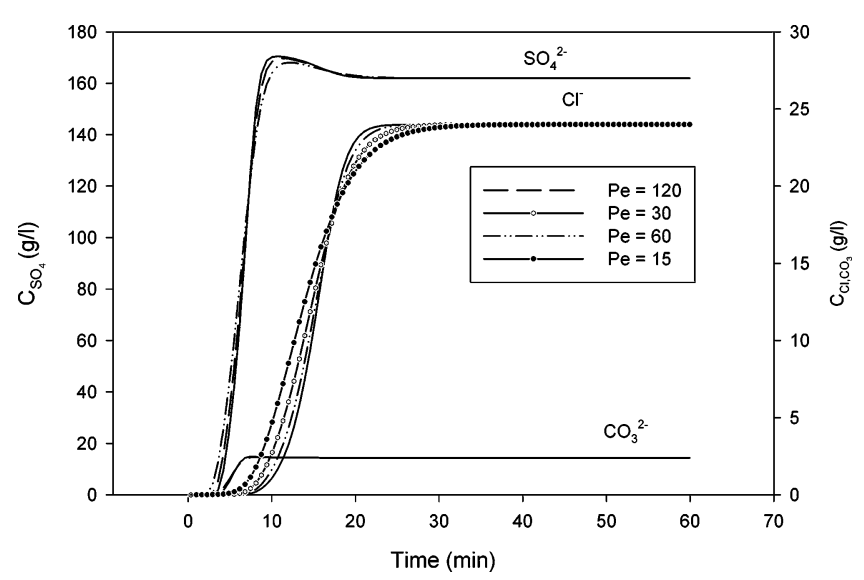

Figure 7. Simulated breakthrough curves for a ternary mixture of $\mathrm{Cl}^{-}, \mathrm{SO}_{4}{ }^{2-}$, and $\mathrm{CO}_{3}{ }^{2-}$ : Effect of Peclet number.

function of the hydrodynamic conditions in the bed and of the resin packing. Mixing within the bed increases when the Peclet number decreases. As a consequence, the spreading of the concentration profiles inside the bed increases, and breakthrough occurs earlier, as can be seen in Figure 7; the effect is especially visible for the chloride curve, as chloride is more extensively adsorbed than sulfate and carbonate.

4.4. Saturation Simulation. Effect of Chloride Concentration in the Feed. The effect of the chloride concentration in the feed is shown in Figure 8 for three different $\mathrm{Cl}^{-}$levels within the typical concentration range for the chloride species in the ESP ash. It should be noted that the breakthrough time is only slightly 


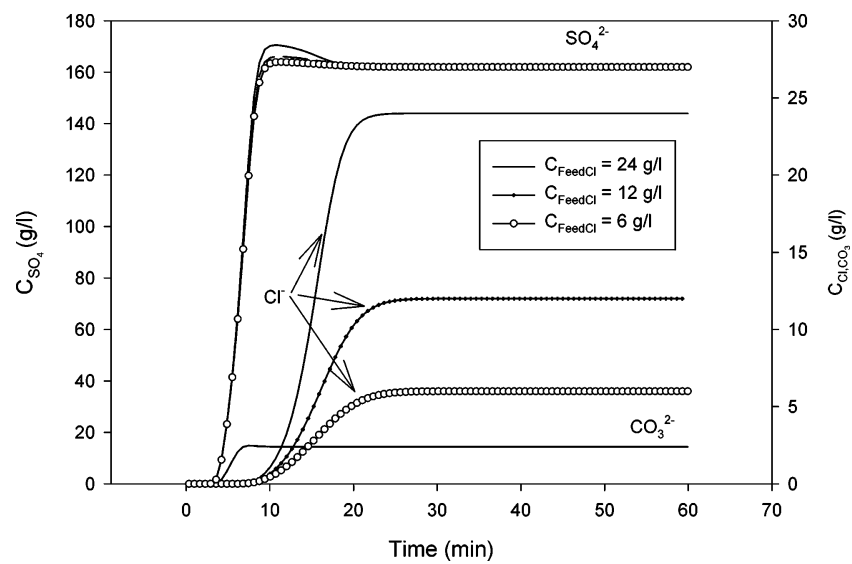

Figure 8. Simulated breakthrough curves for a ternary mixture of $\mathrm{Cl}^{-}, \mathrm{SO}_{4}{ }^{2-}$, and $\mathrm{CO}_{3}{ }^{2-}$ : Effect of chloride feed concentration.

affected, whereas the chloride concentration histories result in increasingly sharp curves as the chloride feed concentration increases. This is probably due to the influence of the differences in the adsorption equilibrium for the three components at higher chloride concentrations in the mixture and the lower tendency toward spreading of the concentration waves during the dynamics of the saturation process.

4.5. Cyclic Operation. Effect on the Adsorption Capacity of the Resin. The effect of cyclic operation on the adsorption capacity (aging) was evaluated by performing a cyclic experiment of saturation followed by regeneration steps at conditions equivalent to those used in industry. The results are shown in Figure 9. Although the possible number of cycles performed at the laboratory scale is limited when compared to a full-scale operation, this set of cycles was valuable for assessing the resin behavior in the first days of operation and for collecting data on process conditions for a possible scaleup of the technical solution.

During the cyclic operation experiment, the resin was exposed to 362 cycles, each of $12 \mathrm{~min}$ total time (saturation + regeneration), corresponding to approximately 3 days of continuous labor. The chloride removal efficiency along the experiments was always greater than $89 \%$, corresponding to an average resin capacity of $0.6 \mathrm{mmol}$ of $\mathrm{Cl}^{-}$per gram. The variation in the resin capacity was associated with the varying composition of the ash solution fed to the column. Finally, it was possible to determine an average sulfate loss of $26 \%$, with a maximum loss of $33 \%$.

4.6. Flowsheet and Process Economics. A plant was designed to demonstrate the scale-up viability on the basis of experimental data obtained in this work. Figure 10 shows a schematic flowsheet of the process with results corresponding to the overall material balance that was calculated on the basis of the following assumptions: (i) an incoming flow rate of 3 tons of precipitator ash per hour and (ii) a 90\% removal of chloride by the system, accompanied by a $70 \%$ recovery of sodium sulfate. The plant basically consists of an ionexchange column containing a certain amount of amphoteric resin, a filter, two dissolving tanks, and two tanks for feed and product solutions. The only utility used for this process is water for dissolving the ash at a temperature of $45^{\circ} \mathrm{C}$. A nearly saturated solution with approximately $300 \mathrm{~g}$ of solids $/ \mathrm{kg}$ of water is produced. The ash solution is fed to a filter where insoluble solids are removed. After this step, the filtered solution is pumped up through the resin bed to remove sodium chloride. The purified solution $\left(\mathrm{SO}_{4}{ }^{2-} / \mathrm{CO}_{3}{ }^{2-}\right)$ is collected and recycled back to recovery. The resin is regenerated with water, producing a $\mathrm{NaCl}$-rich stream that is sent to the general wastewater treatment plant.

A preliminary economic analysis was performed to compare the operating costs of purging of ash with two methods for chloride removal: ion exchange and evaporation/crystallization. Considering a Portuguese pulp mill that discards one-third of the total amount of ash (5 tons/h) generated from electrostatic precipitator for controlling the chloride levels in the recovery cycle, this causes a loss of about 10354 tons/year of sodium sulfate with a cost estimated at approximately $\$ 1,140,000 /$ year. In comparison, the use of the ion-exchange system to treat 3 tons/h of ash would cause a loss of 5591 tons/ year of $\mathrm{Na}_{2} \mathrm{SO}_{4}$, corresponding to a savings of over

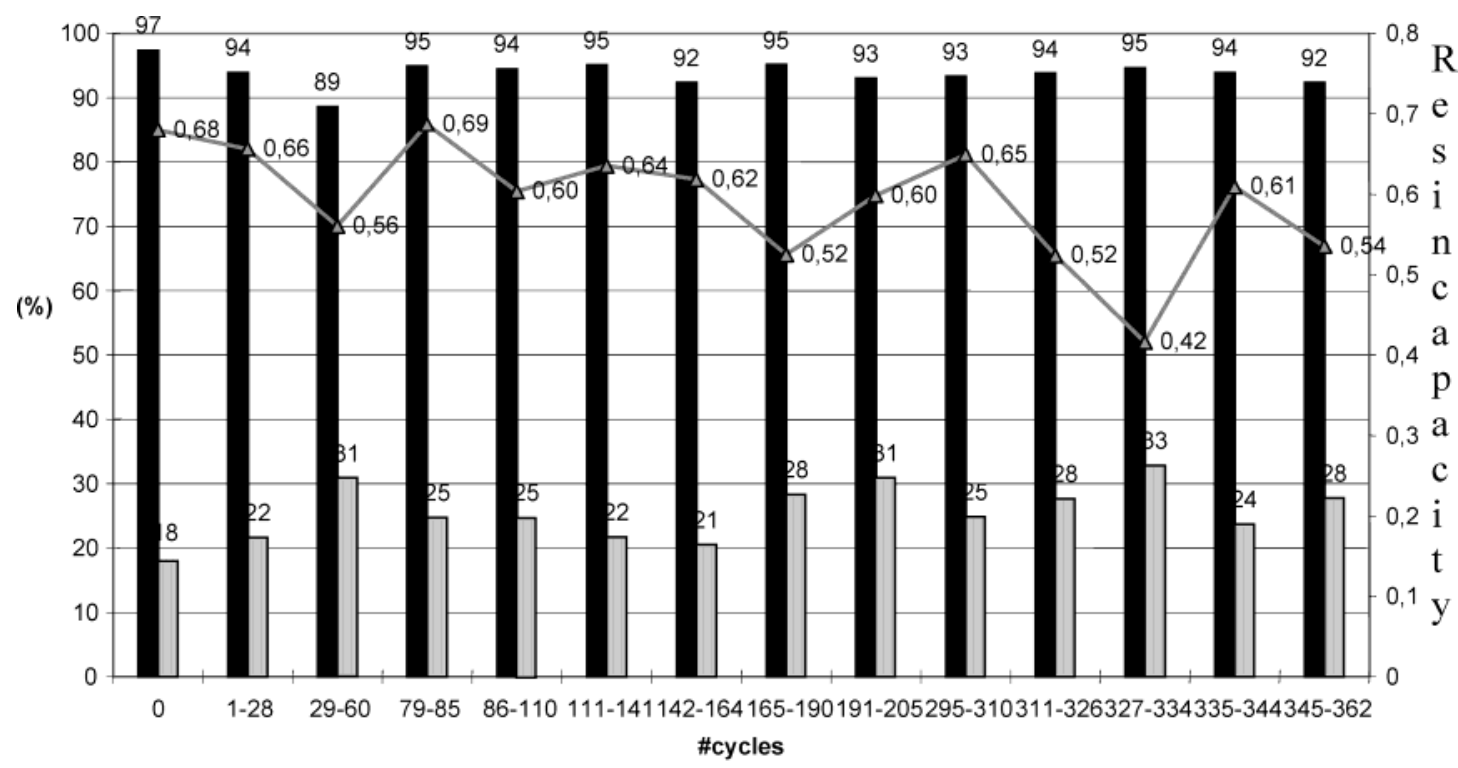

- $\mathrm{Cl}^{-}$removal $\square \mathrm{SO}_{4}{ }^{2-}$ loss $-\Delta$-resin capacity (mmol/g)

Figure 9. Chloride removal efficiency, sulfate loss, and resin capacity during cyclic operation. 


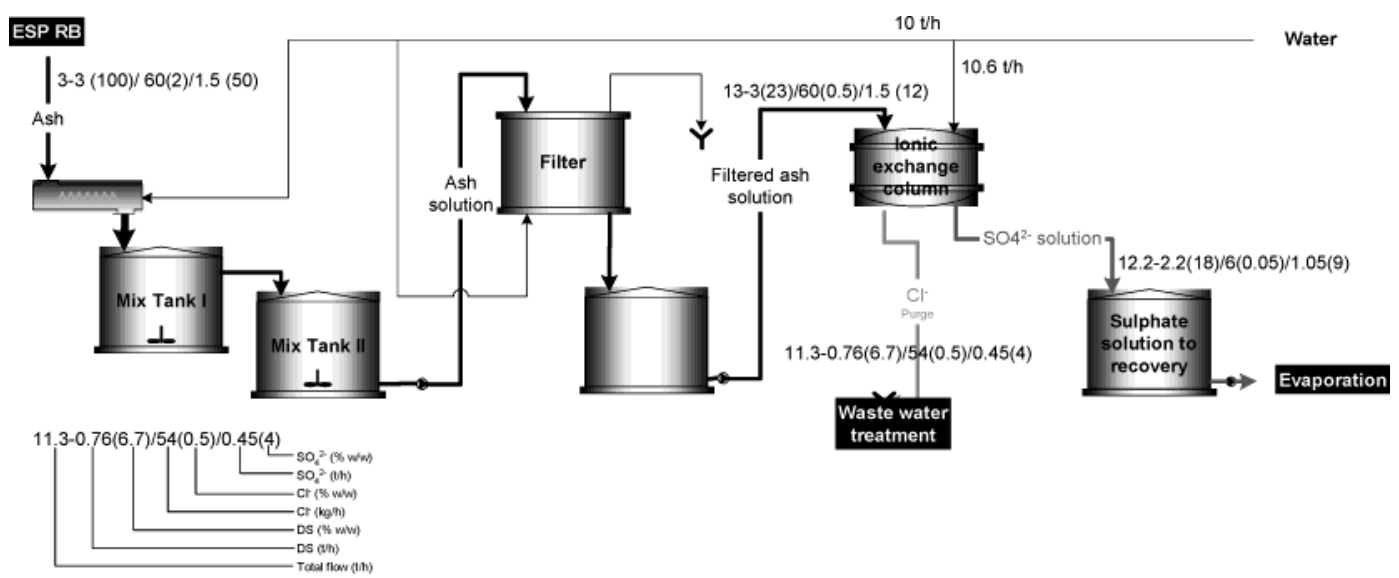

Figure 10. Schematic flowsheet of the ion-exchange process.

$\$ 500,000 /$ year. A higher savings (> $\$ 600,000 /$ year) is obtained in the case of the application of a PDR (precipitator dust recovery) process based on evaporation/crystallization, according to the performance data reported by Minday et al. ${ }^{8}$ However, the operating costs for this process, about $\$ 288,000 / y e a r$, are greater than those for ion exchange. These costs for the process studied, which include resin replacement, water, electricity, steam consumed in the evaporation plant, and lost enthal py in the recovery boiler due to extra water, were estimated to be $\$ 137,000 /$ year. Moreover, the capital investment was estimated to be $\$ 400,000$.

\section{Conclusions}

Excessive accumulation of chloride in the kraft recovery cycle of pulp mills is a serious concern. In this work, we have studied an ion-exchange process based on an amphoteric resin that selectively removes chloride from the ash generated by the recovery boiler. Saturation and regeneration experiments were performed under two different flow rates. Because the resin used presents a greater affinity for $\mathrm{Cl}$, the chloride breakthrough curve arises at a longer time than those for the other components (sulfate and carbonate), and chloride can be efficiently removed during the saturation process. Also, in this step, a $\mathrm{SO}_{4}{ }^{2-} / \mathrm{CO}_{3}{ }^{2-}$-rich stream is recovered that would be available to be returned to the recovery cycle. It is shown that the use of water as the regenerant leads to the rapid and complete elution of species from the resin.

A mathematical model considering dispersed plug flow for the bulk liquid, external mass-transfer resistance, intraparticle mass transfer by pore diffusion, and instantaneous equilibrium of adsorption at the pore/wall interface was presented to simulate the fixed-bed saturations. The model yiel ds results that are in reasonable agreement with experimental data, and it was successfully tested in simulations of the process dynamics for different values of axial dispersion and chloride feed concentration.

The resin performance was not affected during cyclic operation, in which the chloride removal efficiency was always larger than $89 \%$ while the sulfate recovery varied between 67 and $74 \%$. On the basis of these results, obtained at the laboratory scale, which can be easily extrapolated to larger scales, one can conclude that the studied process can provide a true industrial alternative to the problem of the selective removal of chloride in the ash captured from the electrostatic precipitator (ESP) of the recovery boiler of pulp mills.

\section{Acknowledgment}

L.M.G.A.F. thanks Ing. Ana Paula Egas for her assistance with work of fitting of adsorption isotherms to the experimental equilibrium data as well as Prof. J osé Miguel Loureiro, University of Porto, Porto, Portugal, for his assistance with this manuscript.

\section{Nomenclature}

$\mathrm{C}=$ solute concentration in the fluid phase, $\mathrm{mmol} / \mathrm{L}$

$D_{a x}=$ axial dispersion coefficient, $\mathrm{cm}^{2} / \mathrm{s}$

$D_{p}=$ intraparticular diffusion coefficient, $\mathrm{cm}^{2} / \mathrm{s}$

$D_{m}=$ molecular diffusivity, $\mathrm{cm}^{2} / \mathrm{s}$

$\mathrm{k}_{\mathrm{f}}=$ film mass-transfer coefficient, $\mathrm{cm} / \mathrm{s}$

$\mathrm{L}=$ bed height, $\mathrm{cm}$

$\mathrm{N}_{\mathrm{D}}=$ number of mass-transfer units transferred by pore diffusion

$\mathrm{N}_{\mathrm{f}}=$ number of film mass-transfer units

$\mathrm{Pe}=$ axial Peclet number

$q=$ adsorbed solute concentration in equilibrium with the

liquid concentration, $\mathrm{mmol} / \mathrm{g}$ of wet resin

$\mathrm{r}=$ radial coordinate, $\mathrm{cm}$

$\mathrm{R}=$ particle radius, $\mathrm{cm}$

$\mathrm{t}=$ time, $\mathrm{s}$

$\mathrm{u}=$ bed superficial velocity, $\mathrm{cm} / \mathrm{s}$

$\mathrm{u}^{*}=$ normalized radial coordinate $(\mathrm{r} / \mathrm{R})$

$\mathrm{U}=$ volumetric flow rate, $\mathrm{cm}^{3} / \mathrm{min}$

$\mathrm{X}=$ dimensionless solute concentration in the bulk liquid phase $\left(C / C_{E}\right)$

$X_{p}=$ dimensionless solute concentration in theliquid inside

the pores $\left(C_{p} / C_{E}\right)$

$\mathrm{z}=$ bed axial coordinate, $\mathrm{cm}$

$z^{*}=$ normalized axial coordinate ( $\left.\mathrm{z} / \mathrm{L}\right)$

Greek Letters

$\epsilon=$ bed porosity

$\epsilon_{\mathrm{p}}=$ particle porosity

$\rho_{\mathrm{h}}=$ wet density of the adsorbent, $\mathrm{g} / \mathrm{cm}^{3}$

$\theta=$ normalized time $(\mathrm{t} / \tau)$

$\tau=$ space time, $\mathbf{s}$

Subscript

$f=$ feed conditions

\section{Literature Cited}

(1) Soderhjelm, L.; Hausalo, T. Extensive analysis of strong black liquor. Appita 1996, 49, 263. 
(2) Adams, T. N.; Frederick, W.; Grace, T. Kraft Recovery Boilers; Adams, T. N., Ed.; TAPPI Press: Atlanta, GA, 1997.

(3) Tran, H. N.; Barham, D.; Reeve, D. W. Chloride and potassium in the kraft chemical recovery cycle. Pulp Pap. Can. 1990, 91, T185.

(4) Tran, H. N. How Does a Kraft Recovery Boiler Become Plugged? Tappi J . 1986, 69, 102

(5) Moy, W. A.; J oyce, P.; Styan, G. E. Removal of sodium chloride from kraft recovery systems. Pulp Pap. Can. 1974, 75, 88.

(6) Shenassa, R.; Douglas, W.; Dick, P.; Costa, M. Chloride and potassium control in closed kraft mill liquor cycles. Pulp Pap. Can. 1996, 97, T173.

(7) Rapp, H.; Pfromm, P. H. Electrodialysis for chloride removal from the chemical recovery cycle of a kraft pulp mill. J . Membr. Sci. 1998, 146, 249.

(8) Minday, A. M.; Reid, D. W.; Brown, C. J . An overview of various strategies for balancing salt cake, chloride and potassium levels in an ECF kraft mill. In Tappi Conferences-Minimum Effluent Mills Symposium; TAPPI Press: Atlanta, GA, 1997; $\mathrm{p} 115$.

(9) J emaa, N.; Paleologou, M.; Thompson, R.; Richardson, B.; Brown, C.; Sheedy, M. Chloride removal from the kraft recovery boiler ESP dust using the precipitator dust purification (PDP) syste. Pulp Pap. Can. 1999, 100, T219.

(10) Sharp, W. B. A. Anticipated effects of system closure on corrosion in chemical recovery equipment. Tappi J . 1996, 79, 161.

(11) Reeve, D. W.; French, K. A.; Rapson, W. H. The effluent free bleached kraft pulp mill. Part IV. The salt recovery. Pulp Pap. Can. 1974, 75, T293.

(12) Henricson, K.; Kiiskila, E.; Virkola, N. E. Studies of green liquor cooling crystallization and its application to $\mathrm{NaCl}$ removal from the pulping chemical recovery systems. Pap. Puu 1975, 57, 643.

(13) Blackwell. B.; Hitzroth, A. Recycle of bleach plant extraction stage effluent to the kraft liquor cycle: A theoretical analysis. In Environmental Issues and Technology in the Pulp and Paper Industry, A TAPPI Press Anthology of Published Papers 19911994; TAPPI Press: Atlanta, GA, 1995; p 227.

(14) Ferreira, L. G. A.; Soares, M. A. R.; Egas, A. P.; Castro, J . A. M. Selective removal of chloride and potassium in kraft pulp mills. TAPPI J . 2003, 2, 21.

(15) Bellot, J. C.; Condoret, J. S. Modeling of liquid chromatography equilibria. Process Biochem. 1993, 28, 365.

(16) Madsen, N. K.; Sincovec. R. F. PDECOL: General collocation software for partial differential equations. ACM Trans. Math. Software 1979, 5, 326.

(17) Robinson, R. A.; Stokes, R. H. Electrolyte Solutions; Butterworth: London, 1959.

(18) Wakao, N.; Smith, J. Diffusion in catalyst pellets. Chem. Eng. Sci. 1962, 17, 825.

(19) Analytical Grade AG 11 A8 Instruction Manual; Bio-Rad Laboratories: Hercules, CA, 2000.

(20) Rice, R. G.; F oo, S. C. Sorption equilibria and rate studies on resinous retardation beads. 1. Equilibrium studies. Ind. Eng. Chem. Fundam. 1979, 18, 63.

Received for review December 3, 2003

Revised manuscript received August 6, 2004 Accepted August 7, 2004

IE 030862] 